\title{
O atendimento educacional especializado na constituição do autoconceito de pessoa superdotada
}

\author{
Specialized educational care in the constitution of the gifted person's self- \\ concept
Atención educativa especializada en la constitución del autoconcepto del superdotado

Christianne Rocio Storrer Oliveira

Doutoranda pela Universidade Federal do Paraná, Curitiba, PR, Brasil

E-mail: psilara@gmail.com ORCID: https://orcid.org/0000-0003-0262-2842

Maria de Fatima Joaquim Minetto

Professora doutora da Universidade Federal do Paraná, Curitiba, PR, Brasil

E-mail: fa.minetto@gmail.com ORCID: https://orcid.org/0000-0002-6796-1610

Recebido em 09 de agosto de 2021

Aprovado em 24 de setembro de 2021

Publicado em 27 de dezembro de 2021

\section{RESUMO}

Este artigo é recorte de uma pesquisa e tem como objetivo traçar relações entre o atendimento educacional especializado e a construção de uma identidade de pessoa superdotada. Os participantes foram quatro superdotados, com idade entre 19 e 22 anos, dois rapazes e duas moças, dois alunos oriundos do ensino público e dois que cursaram a educação básica em instituições privadas. Todos realizaram processo investigativo de potencial cognitivo antes de finalizar a etapa dos anos iniciais do Ensino Fundamental. A coleta de dados se deu em modo remoto. Os instrumentos foram questionários e inventários, bem como relatórios de avaliação dos participantes, sendo que a entrevista semiestruturada forneceu os dados que basearam as análises presentes nesse artigo. Foi possível apurar a importância da participação no atendimento educacional especializado, no que diz respeito ao desenvolvimento de elementos tais como autoconceito, autorreferência e senso de pertencimento. Ainda foi possível verificar que o precoce senso de identidade do superdotado pode ser entendido como fator protetivo ao seu desenvolvimento socioemocional. $\mathrm{O}$ atendimento educacional especializado, entendido como suporte social, também pode ser colaborador no desenvolvimento das habilidades sociais. Por fim, compreendeu-se que, nos casos descritos, a superdotação pôde ser compreendida como um fator de proteção ao desenvolvimento das habilidades socioemocionais no jovem superdotado adulto.

Palavras-chave: Altas Habilidades/Superdotação; Atendimento Educacional Especializado; Habilidades Socioemocionais. 
http://dx.doi.org/10.5902/1984686X67141

\section{ABSTRACT}

This article is part of one research and its objective was to trace the relationship between specialized educational assistance and the construction of an identity as a gifted person. The participants were four gifted, aged between 19 and 22, two boys and two girls, two students from public education, and two who attended basic education in private institutions. All performed an investigative process of cognitive potential before completing the stage of the early years of elementary school. Data collection took place remotely. The instruments were questionnaires and inventories, as well as participant evaluation reports, and the semistructured interview provided the data that based the analyzes present in this article. It was possible to ascertain the importance of participation in specialized educational care, with regard to the development of elements such as self-concept, self-reference, and a sense of belonging. It was also possible to verify that the precocious sense of identity of the gifted can be understood as a protective factor for their socio-emotional development. Specialized educational assistance, understood as social support, can also collaborate in the development of social skills. Finally, it was understood that, in the cases described, giftedness could be understood as a protective factor for the development of socio-emotional skills in gifted young adults.

Keywords: Giftedness; Specialized educational service; Socio-emotional skills.

\section{RESUMEN}

Este artículo es parte de una investigación y tiene como objetivo trazar la relación entre la asistencia educativa especializada y la construcción de una identidad como superdotado. Los participantes fueron cuatro superdotados, de entre 19 y 22 años, dos niños y dos niñas, dos estudiantes de educación pública y dos que cursaron educación básica en instituciones privadas. Todos realizaron un proceso de investigación del potencial cognitivo antes de completar la etapa de los primeros años de la escuela primaria. La recopilación de datos se realizó de forma remota. Los instrumentos fueron cuestionarios e inventarios, así como informes de evaluación de los participantes, y la entrevista semiestructurada previsto los datos que fundamentaron los análisis presentes en este artículo. Se pudo constatar la importancia de la participación en la atención educativa especializada, en cuanto al desarrollo de elementos como el autoconcepto, la autorreferencia y el sentido de pertenencia. También se pudo comprobar que el precoz sentido de identidad de los superdotados puede entenderse como un factor protector para su desarrollo socioemocional. La asistencia educativa especializada, entendida como apoyo social, también puede colaborar en el desarrollo de habilidades sociales. Finalmente, se entendió que, en los casos descritos, la superdotación podría entenderse como un factor protector para el desarrollo de habilidades socioemocionales en el joven superdotado.

Palabras clave: Altas capacidades/Superdotación; Servicio educativo especializado; Habilidades socioemocionales. 
http://dx.doi.org/10.5902/1984686X67141

\section{Introdução}

Os estudos que se propõem a investigar o superdotado adulto, enfocando sua trajetória acadêmica, suas experiências profissionais e os seus relacionamentos, são muito poucos. Além disso, as pesquisas que enfatizam esses aspectos apresentam resultados que podem ser entendidos como contraditórios (MATTA; GRITTI; LANG, 2019). Isto porque algumas enfocam relações entre a superdotação e desajustes emocionais (OLSZEWSKIKUBILIUS; LEE; THOMSON, 2014), trazendo prejuízos à identificação efetiva ou ao desenvolvimento da pessoa superdotada em aspecto mais global. Outras indicam que as habilidades acima da média podem atuar enquanto fator de proteção ao desenvolvimento socioemocional, o que pode ser verificado na flexibilidade do superdotado a se adaptar a novas situações ou, ainda, à presença de um nível aprimorado de julgamento moral, além da maturidade precoce (CHAGAS-FERREIRA; SOUZA, 2018).

De certo modo, essas posturas antagônicas são trazidas por estudos transversais. Pollet e Schnell (2017) indicam que, quando se colocam em pauta os resultados alcançados em pesquisas longitudinais, não ocorrem diferenças estatísticas significativas em vários dos componentes de bem-estar entre superdotados e participantes não dotados desde a infância até a idade adulta jovem (POLLET; SCHNELL, 2017).

O indivíduo superdotado demonstra um modo diferente de perceber, analisar, agir e reagir às situações e acontecimentos, sendo a sua expressão emocional entendida como mais intensa, quando comparado com seus pares não superdotados (ARANTES-BRERO, 2020). Com um desenvolvimento emocional e moral peculiar, tendo como característica evidente a percepção ampla e profunda do que ocorre em sua vida e no seu entorno (IRUESTE; SACO; NICOLÁS, 2018), o superdotado pode apresentar ações que são entendidas como problemáticas. Indivíduos superdotados podem vir a enfrentar desafios sociais únicos, que, aliado às necessidades emocionais específicas, aumentam a vulnerabilidade das suas competências psicológicas (MATTA; GRITTI; LANG, 2019).

Diante desses pontos, é clara a necessidade de que o indivíduo superdotado, desde criança, tenha acesso a ambientes emocionalmente seguros, a fim de ter 0 desenvolvimento geral aprimorado (GUIMARÃES; OUROFINO, 2007; SABATELLA; CUPERTINO, 2007). A robustez do embasamento teórico é fundamental tanto para o processo de avaliação, quanto para a elaboração das intervenções, pois esses são formados a partir de estudos que mergulham nessa temática. 
http://dx.doi.org/10.5902/1984686X67141

Assim, é necessário partir da adoção de um processo de identificação adequado, aliado a intervenções eficazes, considerando também as necessidades emocionais do superdotado. $O$ enfoque para além do desenvolvimento cognitivo, intelectual ou acadêmico é fundamental, pois as maiores dificuldades percebidas são nos âmbitos social, emocional e afetivo (DESSEN, 2007; VALENTIM; VESTENA, 2017).

É importante ter em conta os desafios que o superdotado encontra ao buscar alcançar seu equilíbrio emocional, sendo esses relacionados com a habilidade excepcional e com a maior amplitude de informações e emoções que acumulam. Não é raro que as emoções estejam além do que eles podem assimilar e processar (BORGES; RODRIGUEZNAVEIRAS; RODRIGUEZ-DORTA, 2018). Na atuação com os indivíduos superdotados, tendo por base os pressupostos do modelo triádico de enriquecimento de Joseph Renzulli, podem ser desenvolvidas atividades que visem o aprimoramento de habilidades intra e interpessoais. Nesse rol de habilidades estão a criatividade, a solução de problemas, as habilidades afetivas, a metacognição e as habilidades de comunicação. Pela compreensão do indivíduo superdotado por meio de uma visão holística, propondo atividades que venham a acurar o aspecto socioemocional, há mais possibilidades de se ampliar as suas potencialidades, tendo também o foco na busca da autorrealização e da satisfação pessoal, além de prevenir riscos ao desenvolvimento psicossocial. (CHAGAS-FERREIRA, 2014; CHAGAS-FERREIRA; SOUZA, 2018).

A política de educação especial (BRASIL, 2011), baseada na perspectiva inclusiva, indica que o aluno com altas habilidades/superdotação compõe, junto aos alunos/as com deficiências e transtornos globais do desenvolvimento, o público-alvo da educação especial. $\mathrm{O}$ atendimento de alunos superdotados em salas de recursos existe desde a década de 1960. Contudo, a organização desse atendimento, tendo em vista as orientações do Ministério da Educação, a partir do Decreto no 7611/2011, preconiza um novo modelo de atendimento, sendo relevante não somente o atendimento do aluno no ambiente da Sala de Recursos Multifuncionais, mas também o assessoramento e parceria integrada com a classe comum, bem como com as famílias (DELOU, 2014). A Resolução № 04/2009 (BRASIL, 2009), traz definições e orientações importantes para o público com altas habilidades/superdotação, tais como a indicação de que os alunos com essa condição devem ser matriculados tanto em classes comuns do ensino regular como no atendimento educacional especializado e prevê as atividades de enriquecimento curricular. 
http://dx.doi.org/10.5902/1984686X67141

O atendimento educacional especializado pode ser considerado fundamental no desenvolvimento do estudante superdotado, levando em consideração tanto os elementos cognitivos e intelectuais, como os que se relacionam aos fatores emocionais e de engajamento. Desse modo, esse suporte vem ao encontro do entendimento das altas habilidades/superdotação num modelo que alia os fatores inteligência, personalidade, contexto sociocultural e o nível de desempenho (PALUDO; LOOS-SANT'ANA; SANT'ANALOOS, 2014). Com o acompanhamento especializado, o superdotado aprimora suas habilidades, favorecendo o fortalecimento de suas características produtivas e relacionadas a sua sensibilidade, criatividade e aprendizagem. É quase impossível pensar que o indivíduo que mostra os indicadores de altas habilidades/superdotação não necessita de orientação e trabalho diferenciado para que possa atingir o máximo de sua produtividade e possa ter estimuladas as áreas do conhecimento em que apresenta maior potencialidade (ARAÚJO; ALENCAR, 2013).

A prática de base do atendimento educacional especializado é a proposição do enriquecimento curricular. De acordo com Renzulli (2014a), as práticas educacionais estruturadas por esse modelo visam desenvolver uma aprendizagem mais interessante, excitante e prazerosa, capaz de promover habilidades de pensamento mais elevadas e criar uma atmosfera escolar que valorize e pratique o que é conhecido como aprendizagem investigativa. $O$ enriquecimento curricular possibilita aos alunos com altas habilidades/superdotação, tanto escolares, como criativo-produtivos, o benefício de acesso a oportunidades educacionais especiais, voltadas para promoção de uma variedade de experiências de aprendizagem enriquecedoras. Habilidades são descobertas e desenvolvidas, proporcionando a expressão ótima das potencialidades do superdotado. Segundo Renzulli (2014b), a história revela que são as pessoas criativas, produtivas e produtoras (e não consumidoras de conhecimento) que atuam em prol do progresso do pensamento em todas as áreas do esforço humano.

Ademais, pode-se considerar que o objetivo da educação do aluno com altas habilidades/superdotação é o emprego máximo de oportunidades às crianças e jovens visando à autorrealização. É crucial que se observe o incentivo ao desenvolvimento e à expressão da combinação de áreas de desempenho em que o potencial superior possa estar presente (RENZULLI, 2014b). Compreende-se, portanto, que um grande desafio aos educadores é transformar o potencial do aluno superdotado em real desenvolvimento. É 
http://dx.doi.org/10.5902/1984686X67141

com esse suporte que o aluno poderá se tornar um adulto atuante, em busca da resolução dos problemas da sociedade contemporânea.

A identificação, realizada de modo a compreender as particularidades do universo contido em cada indivíduo superdotado, remete ao suporte adequado à construção do autoconceito enquanto pessoa superdotada. O atendimento educacional especializado atua de modo a construir, com o desenvolvimento de processos interativos, a identidade do estudante para que ele se compreenda como sujeito e, também, como participante de um grupo formado por pares com características de pensamento, percepção e emocionais similares às suas. A partir disso, o indivíduo, pelo reconhecimento e valorização do outro, passa a crer em suas habilidades, o que acarreta o entendimento de seus planos e objetivos, significando sua vida (PALUDO; LOOS-SANT'ANA; SANT'ANA-LOOS, 2014; SILVERMAN, 2013).

Diante dessas considerações, o presente artigo objetivou analisar as interlocuções entre as produções concernentes às vantagens do acesso do estudante superdotado ao atendimento educacional especializado e os elementos presentes nos discursos de jovens adultos superdotados. A partir dessas análises, foi possível rascunhar o entendimento das relações entre o acesso ao atendimento educacional especializado e a construção da identidade do indivíduo enquanto superdotado. Compreendeu-se que esse movimento encontrou inferências sobre as conveniências desse tipo de programa não só para aperfeiçoamento do desempenho acadêmico, pois seus resultados, quando visualizados em longo prazo, remetem à expressão de funcionamento ajustado na vida.

\section{Método}

Os participantes da pesquisa foram quatro jovens adultos, com idade entre 19 e 22 anos, sendo dois rapazes e duas moças, que apresentaram avaliação comprobatória dos indicadores de AH/SD. A pesquisa teve caráter qualitativo e, corroborando essa condição, o número de participantes não foi fixado a priori, até porque não houve a pretensão de representatividade estatística, mas de busca de casos que conseguissem representar a relevância do fenômeno (FLICK, 2009; SAMPIERI; COLLADO; LUCIO, 2013).

Os dados decorrentes da avaliação de potencial cognitivo foram retirados do documento comprobatório das altas habilidades/superdotação (Relatório ou Parecer), disponibilizado à pesquisadora pelos participantes, e foram essenciais para a elaboração da caracterização desses. Outros instrumentos que fundamentaram a investigação da 
http://dx.doi.org/10.5902/1984686X67141

relação entre o atendimento educacional especializado e a formação do autoconceito de pessoa superdotada foram o Questionário Sociodemográfico e entrevistas semiestruturadas.

O Questionário Sociodemográfico é um instrumento baseado no modelo utilizado nas pesquisas desenvolvidas no Laboratório de Pesquisas em Desenvolvimento Humano ${ }^{1}$. As informações obtidas por meio desse instrumento foram analisadas e permitiram a constituição de categorias, o que possibilitou visão geral dos aspectos pessoais, familiares, sociais, econômicos e acadêmicos do participante. A entrevista semiestruturada foi aplicada visando a coleta de informações a respeito de pontos de vista dos participantes nas seguintes temáticas: a percepção deles da relação entre os indicadores de altas habilidades/superdotação e o seu desempenho acadêmico ou laboral; a informação acerca da participação em algum tipo de atendimento educacional especializado após a identificação enquanto pessoa superdotada, bem como suas percepções acerca desse atendimento; suas percepções a respeito de possíveis diferenças no seu desenvolvimento, expressão emocional e relação com as altas habilidades/superdotação e; sua percepção de pertencimento ao contexto familiar e de suas relações com os familiares.

As questões formuladas para a entrevista semiestruturada objetivaram agregar informações importantes acerca da constituição do superdotado adulto enquanto sujeito e no que diz respeito a sua identidade. As análises propostas configuraram um importante material de investigação, que possibilitou o melhor entendimento de cada participante, no que diz respeito as suas percepções acerca das altas habilidades/superdotação, da sua família e de si próprio. O material proveniente dos questionários sociodemográficos e das entrevistas semiestruturadas foi organizado com a finalidade de proporcionar uma visão mais íntegra de cada participante a partir de seu lugar de indivíduo.

A pesquisa foi realizada em modo remoto, devido às determinações de isolamento social apontadas pelo contexto de pandemia do COVID-19. Os participantes foram convidados por contato via e-mail, que descrevia os objetivos da pesquisa e inquiria sobre sua disponibilidade de participação. Foi encaminhado um vídeo explicativo da pesquisa, elaborado pela pesquisadora, por meio de link do YouTube. Após o retorno dos participantes a respeito de seu entendimento da pesquisa, foram encaminhados os links, tanto do formulário do Termo de Consentimento Livre e Esclarecido (TCLE), como do Questionário Sociodemográfico (QSD). Uma cópia digital do TCLE foi enviada para assinatura digital de todos os participantes. O encontro para a aplicação dos instrumentos 
http://dx.doi.org/10.5902/1984686X67141

foi realizado de modo individual, utilizando-se a plataforma de reuniões online Google Meet, em horário agendado de acordo com a disponibilidade de cada um dos participantes, sendo que o tempo médio para realização da entrevista foi de trinta minutos.

\section{Resultados e discussão}

\section{Caracterização dos participantes}

Os participantes da pesquisa foram dois homens (Morfeu e Eros) e duas mulheres (Deméter e Hebe), sendo todos solteiros. Quando da coleta de dados, a participante mais jovem contava com 19 anos e o mais velho com 22 anos. Deméter e Morfeu tiveram toda a escolarização em escolas da rede pública, Hebe estudou o Ensino Fundamental e Médio em rede privada e, atualmente, cursa o Ensino Superior numa instituição pública. Eros teve toda sua formação acadêmica, incluindo a pós-graduação, em instituições privadas. Tanto Deméter, quanto Morfeu foram encaminhados para avaliação pela psicóloga escolar da rede pública de ensino que estudavam e participaram do atendimento educacional especializado (sala de recursos multifuncionais). Os participantes Hebe e Eros realizaram o processo de investigação em uma instituição privada, mas não foram encaminhados para qualquer serviço educacional especializado de suporte. Eles tiveram acesso somente a atendimentos clínicos durante a sua infância e adolescência. Deméter e Morfeu também tiveram a oportunidade de ter o suporte do atendimento psicológico. Todos eles atualmente apresentam algum diagnóstico de transtorno psíquico, fazendo uso de medicamentos e/ou tendo acompanhamento especializado. Eros informou que somente faz uso de medicação.

Deméter foi encaminhada para o processo de avaliação de potencial cognitivo pela equipe da escola em que estudava, que suspeitava dos indicadores de altas habilidades/superdotação. Na entrevista de anamnese - que é a entrevista inicial, realizada com os responsáveis, que visa obter informações históricas e do desenvolvimento do indivíduo -, os pais informaram que ela poderia ser descrita como uma criança muito ativa, que resolvia as atividades escolares com muita facilidade. Outro ponto de destaque era que Deméter conhecia outras línguas, como Espanhol e LIBRAS, desde a Educação Infantil; ela demonstrava interesse e predisposição para essas aprendizagens. Outras características se baseiam no fato dela ser percebida como uma criança curiosa e resistente a respostas evasivas, com pouca argumentação, por parte dos adultos. Também era fato que ela apresentava compreensão diferenciada das situações do cotidiano. Era descrita como uma 
http://dx.doi.org/10.5902/1984686X67141

criança com grande labilidade emocional, sendo conhecida como alguém que faz tempestade num copo d'água. Mesmo quando pequena, Deméter demonstrava pouco interesse por assuntos usualmente relacionados a sua idade cronológica, expressando que queria muito ser adulta. Os instrumentos formais de avaliação psicológica utilizados na investigação foram a Escala de Inteligência Wechsler para Crianças (WISC-III)², composta por 13 subtestes, dos quais foram aplicados 11 e as Matrizes Progressivas Coloridas de Raven ${ }^{3}$. Os resultados destacaram bom desenvolvimento das aprendizagens informais, com ênfase às capacidades de formação de conceitos, raciocínio lógico-matemático, autonomia e resolução de questões do cotidiano.

A avaliação de Hebe foi realizada quando ela estava cursando a Educação Infantil, pela equipe de uma instituição privada. O parecer concluiu que Hebe apresentava desenvolvimento intelectual, cognitivo e de linguagem significativamente superior. Seu pensamento associativo e a compreensão de inclusão de classes se mostraram muito bem desenvolvidas. Além disso, ela apresentou maturidade de consciência e ótimo conhecimento sobre informações gerais. Mesmo estando na Educação Infantil, Hebe já fazia uso de instrumentos de leitura e escrita, bem como apresentava atenção e percepção em situações diversas, compreendendo, planejando e organizando o pensamento. Foi descrita como uma criança sensível, criativa, vaidosa, responsável e madura para sua idade, tendo sido considerada uma criança superdotada. Numa segunda avaliação, já no ensino superior, Hebe foi avaliada com o uso da Escala de Inteligência Wechsler para Adultos (WAIS-III) ${ }^{4}$, além de outros instrumentos de cunho neuropsicológico. A conclusão desse processo é de que Hebe está categorizada num nível intelectual muito superior em todas as áreas acadêmicas, com predomínio da inteligência espacial e interpessoal, com destaque à inteligência linguística.

Morfeu foi avaliado em seu potencial cognitivo quando tinha 8 anos de idade. Ele foi encaminhado para o processo pela equipe da escola em que estudava, por suspeita de transtornos do comportamento e na aprendizagem. O diagnóstico clínico apresentado era de Transtorno de Déficit de Atenção/Hiperatividade. Para a avaliação psicológica foram utilizados a Escala Wechsler de Inteligência para Crianças (WISC-III) e a CPM - Raven (Matrizes Progressivas Coloridas de Raven). Morfeu apresentou desempenho acima da média, tendo sido caracterizado com o quociente de inteligência (QI) 142. Ele demonstrou domínio dos conteúdos escolares para além do esperado para sua idade e escolaridade, apresentando boa capacidade de atenção concentrada. A capacidade de formação de 
http://dx.doi.org/10.5902/1984686X67141

conceitos e o raciocínio matemático se mostraram muito bem desenvolvidos, sendo que ele teve facilidade para transpor os enunciados para elementos matemáticos. Além disso, teve destaque no desenvolvimento da orientação espacial, percepção todo-partes, raciocínio lógico sequencial. Por fim, no CPM - Raven (Matrizes Progressivas Coloridas de Raven), Morfeu apresentou classificação superior à média, com percentil 95.

A avaliação de potencial cognitivo de Eros foi realizada quando ele cursava a Educação Infantil, por equipe de uma instituição privada. O parecer avaliativo informou que Eros apresentava desenvolvimento tanto intelectual, como cognitivo e de linguagem significativamente superior à média. Sua linguagem expressiva e receptiva era altamente desenvolvida, contando com vocabulário amplo, o que favorecia a habilidade de comunicação e de organização do pensamento. Eros apresentou facilidade de utilização do raciocínio lógico, ótima percepção e compreensão de conceitos. Um fator de destaque é que ele demonstrou características bem desenvolvidas de liderança, bem como bom desenvolvimento das funções executivas. Entre suas características comportamentais foram descritas a cordialidade, o bom senso de humor e a habilidade de trabalhar de forma independente, envolvendo-se em tarefas ou assumindo responsabilidades que fizessem sentido para ele. Diante dos resultados, o parecer é que de Eros era uma criança superdotada e pela análise desses elementos ele caracteriza a condição de superdotação escolar.

\section{Entrevistas}

Os dados coletados nas entrevistas semiestruturadas auxiliaram na investigação, em modo mais aprofundado, da relação entre o acesso dos participantes ao atendimento educacional especializado e a sua construção da identificação enquanto indivíduo superdotado. Segundo Sampieri, Collado e Lucio (2013), é na entrevista que são feitas perguntas sobre as variadas experiências, revelam-se as emoções e os sentimentos, bem como são trazidos à tona os fatos e histórias de vida, associadas às percepções do entrevistado. Quando são compostas de perguntas abertas e neutras, é mais clara a finalidade da obtenção de específicos pontos de vista e de opiniões detalhadas. De acordo com Lüdke e André (2013), a entrevista vai além do processo técnico, pois apresenta uma característica mais amistosa e até íntima. Por ser um instrumento mais flexível, considerase praticamente como uma reunião de troca de informações. Por meio de coleta e análise de dados quantitativos (decorrentes de aplicação de inventários, por exemplo) e de qualitativos (advindos das entrevistas) é intensificado o conhecimento a respeito daquele 
http://dx.doi.org/10.5902/1984686X67141

indivíduo, participante da pesquisa, em suas diversas nuances (LINS; BORSA, 2017). Essa mescla foi a proposta da investigação.

Dois participantes, Deméter e Morfeu, tiveram acesso ao atendimento educacional especializado durante a sua escolaridade básica. Deméter participou do atendimento enquanto cursava as séries iniciais do Ensino Fundamental, sendo que Morfeu foi além, realizando esse atendimento até as séries finais do Ensino Fundamental. A participante Hebe teve acesso a um programa de suporte ao estudante superdotado quando ingressou no Ensino Superior, mas teve acompanhamento de psicóloga desde a identificação da superdotação. Somente Eros não teve acesso a qualquer tipo de programa de suporte ao estudante superdotado, o que pode ser justificado pelo desconhecimento dele acerca da sua condição até a idade de 18 anos.

As entrevistas exploraram de modo mais aprofundado quatro pontos que não tinham sido contemplados pela aplicação dos instrumentos formais (inventários e escala). Dentre estas perguntas, a que investigava a percepção dos participantes a respeito da participação em atendimento educacional especializado era: Durante a sua vida escolar você teve acesso ao atendimento educacional especializado para estudantes com Altas Habilidades/Superdotação? Qual é a sua opinião a respeito da importância desse atendimento na sua construção de identidade enquanto uma pessoa superdotada? A análise das respostas foi agrupada num eixo temático denominado Importância do atendimento educacional especializado na construção da identidade da pessoa superdotada. O esquema das respostas pode ser mais bem visualizado na figura 1 .

Figura 1 - Sumarização dos temas elencados na entrevista semiestruturada, a respeito da relação entre o atendimento educacional especializado e a construção da identidade da pessoa superdotada

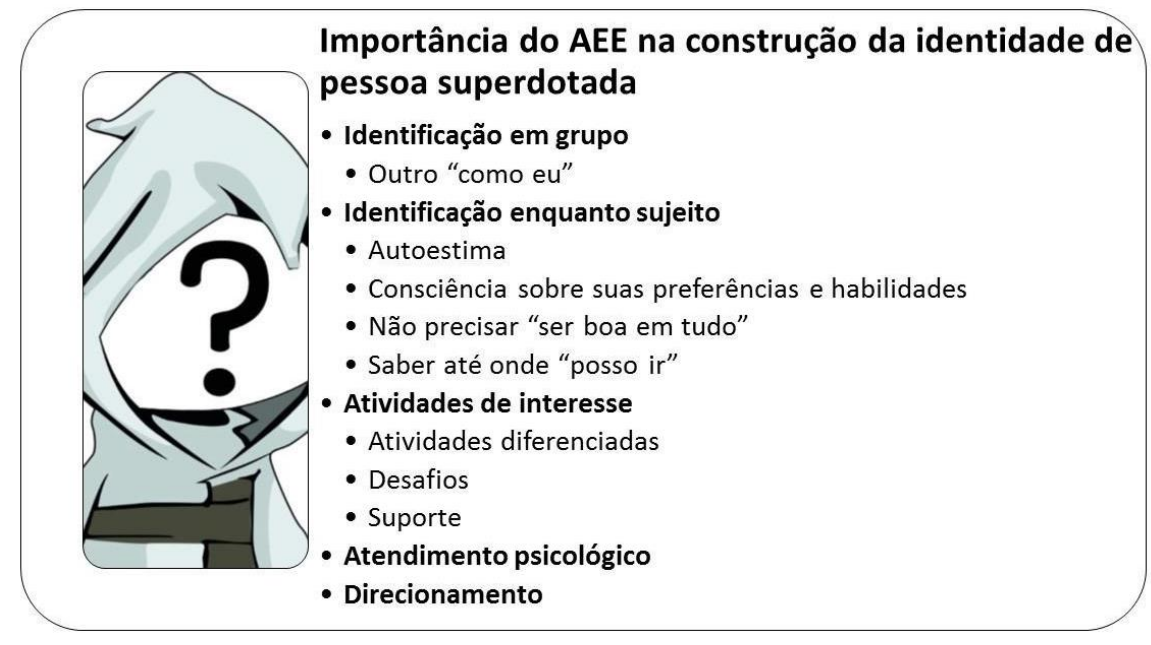

Fonte: As autoras (2021). 
http://dx.doi.org/10.5902/1984686X67141

Mesmo que não tivessem participado de algum tipo de programa de apoio ao superdotado, no transcurso da educação básica, Hebe e Eros explanaram seus pontos de vista a respeito dessa temática. As respostas desses participantes compuseram os dois últimos temas (atendimento psicológico e direcionamento).

Quando se observa o primeiro tópico, referente à identificação em grupo, tanto Deméter, como Morfeu, evidenciaram a importância de terem tido acesso a esse tipo de acompanhamento.

(...) porque se eu achasse que era só eu, a estranha, que não existisse mais ninguém como eu, eu ia me sentir muito mal comigo mesma. Porque imagina, todo mundo normal e você esquisita lá no meio. Tem outros esquisitos igual a mim, então tá tranquilo. (DEMÉTER)

Eu acho que foi uma das coisas mais importantes que me aconteceram, para aprender a lidar com algumas características. Muitas vezes, as pessoas, pela manifestação que a superdotação tem possibilidade de causar problemas comportamentais. Eu imagino que por você estar inserido num ambiente com pessoas parecidas com você... a parte da interação social também é muito importante. Foi importante para mim também porque eu me sentia muito excluído e lá eu conseguia conversar. (MORFEU)

Já quando se enfatiza a identificação enquanto sujeito, os subtemas relevantes observados foram: 'autoestima', 'consciência sobre suas preferências e habilidades', 'não precisar ser boa em tudo' e 'saber até onde pode ir'. Hebe não participou de programa de apoio, mas sempre teve acompanhamento psicológico e teve adaptações e propostas diferenciadas de estudo na escola em que estudou durante o Ensino Fundamental, o que traz como relevante ao seu desenvolvimento escolar. Hebe trouxe em seu discurso:

\begin{abstract}
Eu passei 7 anos no S. M., eu sempre senti esse apoio, de ter, educacionalmente falando, um suporte muito bom, até o momento em que eu não precisava mais. (...) Com certeza ajudou. Pra você ver que não é boa em tudo. (...) Ter esse acompanhamento contribuiu, pra eu ver que não era burra, mas que eu precisava ver a conta. Ajudou a me entender que eu tenho dificuldade. (...) Ter tido esse suporte numa fase da vida que eu precisava mais, que eu sentia mais diferença, eu precisava de mais direcionamento. Não é porque eu sou superdotada que eu sei tudo, não é porque eu sou superdotada que eu não vou ter uma nota ruim, que eu não vou entender determinado conteúdo. $E$ tá tudo bem em relação a isso. (HEBE)
\end{abstract}

$\mathrm{O}$ item que traz as atividades de suporte indica que $\mathrm{O}$ atendimento educacional especializado se constitui enquanto um elemento fundamental para que sejam descobertas as potencialidades do estudante, principalmente por meio do acesso a atividades extra ao contexto escolar. Quanto a isso, os participantes Morfeu e Deméter expuseram os seguintes pontos: 
http://dx.doi.org/10.5902/1984686X67141

A atividade que eu mais gostava era o RPG de mesa e eu faço isso até hoje. (MORFEU)

Até o $5^{\circ}$ ano, que foi no $\mathrm{C}$., eu fazia muitas coisas interessantes, a gente pesquisava, porque a gente tava tentando descobrir em que área eu me destacava. (DEMÉTER)

Eros comentou acreditar que deveria ter feito o atendimento, não compreendendo as razões pelas quais os pais não possibilitaram isso a ele. Ele comenta que entende que o atendimento educacional especializado seria uma forma de direcionamento ao desenvolvimento, para uma espécie de treino das suas habilidades.

Olha, eu vou dar uma explicação do que eu acho. Acho que tem dois tipos de aprendizado: o de andar de bicicleta e o do inglês, por exemplo. $O$ do inglês, se você não pratica, você esquece. Eu acho que as habilidades é que nem o aprendizado do inglês. É como se fosse um músculo, tem que treinar. Eu não vou julgar se tá certo ou errado não ter feito um acompanhamento, sei lá... acho que passou, mas eu acho que deveria ter feito. Acho que poderia fazer uma diferença não só na questão da identidade, mas na questão do desenvolvimento. É um músculo que não foi usado. Hoje eu não tenho como saber se ia mudar alguma coisa ou não ia mudar nada. Pode ser que mudasse. Eu não consigo achar um motivo pra não ter feito (...). Dava pra fazer alguma coisa ali. Alguma coisa poderia ter feito, teria sido útil. (EROS)

O quadro 1 traz pontos de destaque das respostas dos participantes à referida questão.

Quadro 1 - Sumário das respostas dos participantes à importância do atendimento educacional especializado na construção da identidade enquanto uma pessoa superdotada

\begin{tabular}{|l|l|}
\hline PARTICIPANTE & \multicolumn{1}{c|}{ PONTOS PRINCIPAIS } \\
\hline Deméter & $\begin{array}{l}\text { Ela comentou que teve atendimento educacional especializado contínuo quando estava nos } \\
\text { anos iniciais do Ensino Fundamental. Nos anos finais foi somente no } 6^{\circ} \text { ano e retornou, por } \\
\text { pouco tempo, no 10 ano do Ensino Médio. Ela viu vantagem no atendimento quando pequena, } \\
\text { porque estavam pesquisando quais seriam suas áreas de destaque. No atendimento quando } \\
\text { mais velha, não percebeu que auxiliava e não continuou. Em relação aos benefícios de ter } \\
\text { participado do atendimento, vê que foi bom para saber que não era só ela, que há outros como } \\
\text { ela. }\end{array}$ \\
\hline Hebe & $\begin{array}{l}\text { A equipe da escola que ela frequentou no Ensino Fundamental fez parceria com a equipe do } \\
\text { instituto que Hebe fez a avaliação, o que fez com que ela tivesse todas as adequações no } \\
\text { âmbito escolar. Contudo, nunca teve atendimento individualizado focado no aspecto }\end{array}$ \\
& $\begin{array}{l}\text { acadêmico. Há um projeto na universidade em que estuda, mas ela não conseguiu participar. } \\
\text { Comenta que é graças ao atendimento psicológico durante todo o transcurso de vida que ela } \\
\text { conseguiu se conhecer e aprendeu a organizar estratégias para seu melhor desempenho. }\end{array}$ \\
\hline Morfeu & $\begin{array}{l}\text { Realizou atendimento educacional especializado e comenta que foi uma das coisas mais } \\
\text { importantes que aconteceram na vida dele, porque estava inserido num ambiente com } \\
\text { pessoas parecidas com ele. Vê a interação social como importante, porque se sentia excluído } \\
\text { e em atendimento conseguia conversar. Comenta que na escola atual tem um programa de } \\
\text { suporte aos alunos que apresentam diferenças em seus processos de aprendizagem, mas que } \\
\text { não funciona a contento. }\end{array}$ \\
\hline Eros & $\begin{array}{l}\text { Ele não teve acesso ao atendimento educacional especializado, até por ter tido conhecimento } \\
\text { dos indicadores de AH/SD somente aos } 18 \text { anos. Acha que poderia ter feito diferença se } \\
\text { tivesse tido acesso ao atendimento, até para desenvolver melhor suas habilidades. }\end{array}$ \\
\hline
\end{tabular}

Fonte: As autoras (2021). 
http://dx.doi.org/10.5902/1984686X67141

\title{
A construção enquanto indivíduo superdotado
}

Por meio das entrevistas semiestruturadas, foi possível realizar uma análise mais profunda dos dados, fazendo com que a investigação clarificasse a relação entre a possibilidade dos participantes de participarem de atendimento educacional especializado e a sua identificação enquanto indivíduo superdotado.

Nos resultados de Hebe e Eros, pôde ser percebido o desenvolvimento do autoconceito, claro elemento que auxilia no processo de formação da identidade. Em entrevista, Hebe comentou a respeito da sua percepção acerca de ser superdotada, sabendo lidar com as situações decorrentes dessa condição e valorizando esse elemento, mais até do que ter a alta capacidade. Ela não participou de um programa específico de atendimento educacional especializado, mas diante das adequações visando o enriquecimento curricular (propostas pela escola), aliado ao processo psicoterapêutico desde criança, compreende-se a importância desses para o seu entendimento de suas peculiaridades. Isto fica bastante claro no discurso da participante.

\begin{abstract}
Mas eu acho que ter feito acompanhamento psicológico desde cedo, sabe, saber da superdotação desde cedo, me ajudou justamente a entender... não, ok, eu que fui demais. Às vezes eu ir demais cabe dentro de uma prova, por exemplo, mas às vezes não. Então essa coisa de tentar balancear até onde eu posso ir. Isso é algo que o acompanhamento psicológico ajudou. Mas eu vejo que a parte boa, não só da superdotação em si, mas de eu saber lidar com ela, é que eu consigo saber como eu funciono. (...) Por exemplo, a minha mãe respeita muito e sempre me incentiva muito a não me cobrar tanto, sabe? Aceitar erros e etc. (HEBE)
\end{abstract}

Deméter e Morfeu, por sua vez, participaram de atendimento educacional especializado e compreendem o valor dessa atividade para o seu desenvolvimento.

Quando eu saí do P. L. eu saí (do atendimento), mas eu não queria parar. Eu fazia (atendimento) no I. E. P.. Eu acho que foi uma das coisas mais importantes que me aconteceram, para aprender a lidar com algumas características. Muitas vezes, as pessoas, pela manifestação que a superdotação tem possibilidade de causar problemas comportamentais. Eu imagino que por você estar inserido num ambiente com pessoas parecidas com você... a parte da interação social também é muito importante. Foi importante para mim também porque eu me sentia muito excluído e lá eu conseguia conversar. (MORFEU) 
http://dx.doi.org/10.5902/1984686X67141

Sim, tive (atendimento) contínuo até o $5^{\circ}$ ano. Tive no $6^{\circ}$ ano. No $1^{\circ}$ ano eu fui fazer com a prof. R., daí parei, porque saí do A. B.. Porque não agregou nada. Até o $5^{\circ}$ ano, que foi no M. C., eu fazia muitas coisas interessantes, a gente pesquisava, porque a gente tava tentando descobrir em que área eu me destacava. No fim acabou que a gente não descobriu, porque todas as áreas que eu entrava em contato eu conseguia me adaptar. Qualquer coisa eu consigo me adaptar. (...) Sim (o atendimento agregou), porque se eu achasse que era só eu, a estranha, que não existisse mais ninguém como eu, eu ia me sentir muito mal comigo mesma. Porque imagina, todo mundo normal e você esquisita lá no meio. Tem outros esquisitos igual a mim, então tá tranquilo. (DEMÉTER)

Renzulli (2018) apresenta trabalhos voltados ao desenvolvimento do engajamento e da ética, bem como o de obtenção de um bem comum (equilibrando os interesses intra, inter e extrapessoais). É importante compreender que além do aspecto intelectual, as inteligências social, emocional, intra e interpessoal são também relacionadas ao componente cognitivo. O trabalho a ser realizado deve otimizar esses aspectos, pois é a partir daí que os jovens superdotados serão desafiados a prosperar num sentido de responsabilidade para com a sociedade em geral.

Eren, Çete, Avcil e Baykara (2018), explanam acerca da assincronia entre o desenvolvimento cognitivo e físico. A partir da comparação com as demais crianças, as que são superdotadas apresentam necessidades emocionais e sociais diversas. Os superdotados usualmente são vistos como mais isolados, menos sensíveis aos pensamentos de seus pares e menos adaptados ao ambiente e à sociedade. Com isso, os autores indicam a necessidade de intervenção educacional e suporte psicológico para que estes indivíduos alcancem seu potencial.

Vötter e Schnell (2019), ao analisar um ensaio longitudinal, concluíram que os superdotados aparentemente experimentam um grande desafio quando se coloca em xeque 0 aspecto do pertencimento, tomando por base o fator de significância. Isso quer dizer que adultos que porventura apresentam baixa significância denotam também a percepção de que são desajustados ou diferentes.

Renati, Bonfiglio e Pfeiffer (2017) comentam que a maioria dos estudos foca no papel da família no desenvolvimento do talento, principalmente na perspectiva acadêmica. Entretanto, as pesquisas demonstram que os pais que atuam de forma autoritativa fornecem aos filhos o apoio emocional e a segurança de que precisam para que eles tenham autonomia e estabeleçam relacionamentos saudáveis e gratificantes. Os pais autoritativos lançam mão de sua visão de adulto, mas sem restringir a criança, reconhecendo que esta possui interesses próprios e maneiras particulares. Assim, 
http://dx.doi.org/10.5902/1984686X67141

conseguem promover um modelo educacional que fundamenta a construção de um adulto autônomo, independente e, sobretudo, feliz (BAUMRIND, 1971; WEBER; PRADO; VIEZZER; BRANDENBURG, 2004; OLSZEWSKI-KUBILIUS; LEE; THOMSON, 2014).

Deméter apresentou entendimento pessoal e expressão de habilidades apropriadas para o convívio social muito bem desenvolvidas. O participante Morfeu comentou no Questionário Sociodemográfico que acredita ter reprimido as emoções por conta de os pais enfatizarem a atenção no aspecto do TDAH e não para ele como filho. Ele acredita que sua dificuldade no aspecto emocional é decorrente de uma tentativa de aparentar ser uma criança feliz e normal, para que os pais não se preocupassem com ele. Tanto Deméter, quanto Morfeu, apresentaram, nas entrevistas, pontos de destaque às dificuldades de seu contexto familiar. Destacam-se as afirmativas.

\begin{abstract}
Minha mãe sempre me tratou normal, né, graças a Deus. Ela sempre foi a única que me tratou tranquilo. Meu pai sempre cobrou muito de mim, exigiu a perfeição. (...) Eu sempre busquei ser perfeita, intelectualmente, até uma certa idade, para agradar meu pai (...) Pai, tirei 100! Não fez mais que sua obrigação! Ah, tirei 90. Olha, dá pra melhorar. 99! Dá pra melhorar! (DEMÉTER)
\end{abstract}

\begin{abstract}
Meus pais colocaram o computador na frente, pra ficar monitorando o indivíduo de 21 anos. Eles parecem, de uma forma, superprotetores. Mas não é exatamente isso, é porque eles sempre tiveram que lidar com todas as dificuldades, mas agora que eu consigo lidar com meus problemas sozinho, de um jeito que eles não gostam, eles não querem que eu tome controle da minha própria vida. Como eu vou aprender a lidar com meus problemas se eles não me dão espaço pra eu me lascar. (...) Eles não ligam como eu estou como um todo, só pra parte acadêmica. Eles negligenciam todos os outros pontos, pra dar atenção pra um e acaba mais atrapalhando do que ajudando. (MORFEU)
\end{abstract}

Olszewski-Kubilius, Lee e Thomson (2014), explanam que famílias desengajadas se caracterizam por pouca proximidade, falta de lealdade e alta independência, levando o indivíduo a uma percepção de inadequação dentro daquele sistema. São elementos descritores desse tipo de família a limitação no que diz respeito à intimidade e pouco apoio entre os componentes da família. Os autores comentam ainda a respeito de pesquisas que indicam que é a partir do incentivo ao desenvolvimento social positivo dos filhos que se constroem crianças social e emocionalmente competentes, e que isso é comum em lares onde existe o equilíbrio entre as expectativas claras de comportamento e aplicação consistente de limites bem definidos, além do respeito pelo desenvolvimento individual da criança. Esse é considerado um sistema familiar adaptável, apoiador. As famílias com uma estrutura mais resiliente tendem a ter mais sucesso na promoção dos fatores protetivos no desenvolvimento da criança, tais como autoestima, habilidades de solução de problemas, 
http://dx.doi.org/10.5902/1984686X67141

estratégias de enfrentamento e regulação emocional (RENATI; BONFIGLIO, PFEIFFER, 2017).

Pais de crianças superdotadas encontram os mesmos desafios que os outros pais, quando se trata da adequação das práticas parentais, mas eles têm ainda que lidar com preocupações particulares a respeito do desenvolvimento acadêmico e psicossocial de seus filhos, o que acaba se tornando uma fonte de estresse parental. Diante disso, é importante destacar que o atendimento educacional especializado não é destinado somente ao suporte do estudante. É também ação do professor que atua no atendimento educacional especializado promover o diálogo constante com a família. Cada aluno deve ser respeitado em seu ritmo próprio de aprendizagem, sendo oportunizadas estratégias diversas e promotoras da criatividade. Entre essas estratégias estão o estímulo à curiosidade, realizado por meio de acolhimento, proximidade e se evitando as críticas destrutivas e julgamento prévio à expressão do aluno superdotado. Com esse suporte adequado, o indivíduo superdotado poderá desenvolver a sua identidade enquanto superdotado, bem estabelecer o autoconceito positivo, compreendendo sua condição (MENDONÇA; RODRIGUES; CAPELLINI, 2020).

O que se tem claro, diante das considerações apuradas nas pesquisas da área, é que se faz necessário o estabelecimento de um ambiente promotor da educação adequada para que se implemente o talento potencial. Além disso, é primordial a análise e o elenco de intervenções que resgatem as relações existentes entre aprimoramento das habilidades do superdotado e o acompanhamento próximo da família. (ASPESI, 2007; SILVA; FLEITH, 2008). Silva (2018) é clara ao elucidar a importância de que as famílias com filhos superdotados tenham convívio com outras famílias em situação análoga, incentivando-se a formação de redes de suporte. Isso porque a dinâmica dessas famílias é afetada pelas demonstrações de precocidade do filho superdotado, principalmente quando são evidenciadas a assincronia e as características socioemocionais únicas.

Assim, assimila-se que é a partir da construção da identidade do superdotado, bem como do incremento de seu autoconceito e autorreferência, com o suporte mútuo do atendimento educacional especializado e da família, que será possível compreender o fator superdotação como catalisador de processos psicológicos, que resultarão em um desenvolvimento ótimo e uma adequada expressão socioemocional. Assim, poderá se possibilitar ao indivíduo superdotado a melhor adaptabilidade a situações que demandem de suas habilidades sociais, chegando à boa atuação diante das situações adversas. 


\section{Considerações finais}

Por meio desse trabalho foi possível comprovar, em aspecto de análise individual, o estado do precoce senso de identidade do superdotado como fator de proteção ao seu desenvolvimento socioemocional. Aliado a isso, o estudo em questão informa da importância do suporte social, encontrado em outros ambientes de lazer e estudo do indivíduo superdotado, que pode ser elencado como colaborador no desenvolvimento das habilidades socioemocionais.

$O$ atendimento educacional especializado, para além do desenvolvimento dos talentos habitualmente relacionados aos aspectos acadêmicos, também é responsável pela otimização do desenvolvimento socioemocional do superdotado. As entrevistas semiestruturadas trouxeram respostas, que evidenciaram a importância da participação da criança superdotada no atendimento educacional especializado, com a finalidade de conhecimento de suas habilidades cognitivas e emocionais, com fins de organização de sua identidade enquanto pessoa superdotada. Com isso, promove-se a melhor evolução de suas habilidades socioemocionais. $O$ relato dos participantes que frequentaram 0 atendimento educacional especializado trouxe pontos de pertencimento a um grupo, pois era no atendimento, interagindo com outros superdotados, que percebiam que não eram únicos, peculiares, diferentes. Percebiam que existiam outros como eles.

Alguns estudos trazem a informação de que, na vida adulta, muitos superdotados mostram maturidade psicológica, além de alcance de bons níveis educacionais e socioeconômicos. Outros enfatizam que a alta inteligência se apresenta como fonte de risco para o desenvolvimento afetivo, sendo comum a apresentação, por superdotados, de transtornos relacionados à depressão e à ansiedade. Contudo, mesmo diante do antagonismo de achados nas pesquisas acerca do desenvolvimento emocional do superdotado, é fato que o adequado investimento neste indivíduo, iniciando com um adequado processo de identificação, assim como o acesso e frequência a um atendimento educacional que preze pela construção de sua identidade e alie ações ao estudante e ao aprimoramento das estratégias educacionais de sua família, possibilitará a promoção de um adulto feliz, saudável e com desempenho coeso ao seu potencial. 
http://dx.doi.org/10.5902/1984686X67141

\section{Referências}

ARANTES-BRERO, Denise Rocha Belfort. Altas Habilidades/Superdotação na vida adulta: modos de ser e trajetórias de vida. Curitiba: Juruá, 2020.

ARAÚJO, M. R. de; ALENCAR, M. L. A criatividade no ensino de atenção às diferenças: reflexões acerca da educação de alunos com altas habilidades/superdotação. In:

Revista brasileira de altas habilidades/superdotação. Brasília: ConBraSD. v. 1. nำ1, 2013. p. 67-77. Disponível em http://livrozilla.com/doc/1136427/vers\%C3\%A3o-pdf--revista-brasileira-de-altas-habilidades. Acesso em 10.fev 2020

ASPESI, Cristiana. A família do aluno com altas habilidades/superdotação. In: FLEITH, Denise de Souza. A construção de práticas educacionais para o aluno com Altas Habilidades/Superdotação. Brasília: Ministério da Educação, 2007. p. 29-48.

Disponível em: http://portal.mec.gov.br/seesp/arquivos/pdf/altashab4.pdf Acesso em: 08 ago. 2018.

BAUMRIND, Diana. Current patterns of parental authority. Developmental Psychology, n. 4(1, Pt.2), p. 1-103, Jan. 1971. https://doi.org/10.1037/h0030372. Disponível em: https://psycnet.apa.org/record/1971-07956-001. Acesso em 27 jul. 2020.

BORGES, África.; RODRIGUES-NAVEIRAS, Elena.; RODRIGUEZ-DORTA, Manuela. Ajuste personal y social del alumnado de altas capacidades: evidencias empíricas y respuesta educativa. In: PISKE, F. H. R et al. (orgs.). Educação de superdotados e talentosos: Emoção e criatividade. Curitiba: Juruá, 2018. p. 44-62.

BRASIL. Ministério da Educação. Resolução № 4, de 2 de Outubro de 2009. Disponível em: http://portal.mec.gov.br/dmdocuments/rceb004_09.pdf . Acesso em: 24 jul. 2019.

BRASIL. Presidência da República. Decreto 7611, de 17 de novembro de 2011. Disponível em http://www.planalto.gov.br/ccivil_03/_ato20112014/2011/decreto/d7611.htm. Acesso em 13/09/2017.

CHAGAS-FERREIRA, Jane Farias. As características socioemocionais do indivíduo talentoso e a importância do desenvolvimento de habilidades sociais. In: VIRGOLIM, Angela M.R.; KONKIEWITZ, Elisabete Castelon (orgs.). Altas

Habilidades/Superdotação, inteligência e criatividade: uma visão multidisiciplinar. São Paulo: Papirus, 2014. p. 283-308.

CHAGAS-FERREIRA, Jane Farias; SOUZA, Rhaissa Andrêssa Ramos de. O desenvolvimento socioemocional de superdotados: descrevendo singularidades e identificando possibilidades de atendimento. In: PISKE, Fernanda Hellen Ribeiro; STOLTZ, Tania; COSTA-LOBO, Cristina; ROCHA, Alberto; VÁSZQUEZ-JUSTO, Enrique (orgs). Educação de superdotados e talentosos: Emoção e criatividade. Curitiba: Juruá, 2018. p. 127-138. 
DELOU, Cristina Maria Carvalho. Plano de atendimento educacional especializado integrado ao plano individual de ensino com vistas à aceleração de estudos: Sugestão adaptada do modelo de Joseph Renzulli. In: VIRGOLIM, Ângela M. R.; KONKIEWITZ, Elisabete Castelon (orgs.). Altas habilidades/superdotação, inteligência e criatividade. Campinas: Papirus, 2014. Pp. 411-426.

DESSEN, Maria Auxiliadora. A família como contexto de desenvolvimento. In: FLEITH, Denise de Souza. A construção de práticas educacionais para o aluno com Altas Habilidades/Superdotação. Brasília: Ministério da Educação, 2007. p. 12-28. Disponível em: http://portal.mec.gov.br/seesp/arquivos/pdf/altashab4.pdf Acesso em: 08 ago. 2018.

EREN, Fatma; ÇETE, Ayla; AVCiL, Sibelnur; BAYKARA, Burak. Emotional and behavioral characteristics of gifted children and their families. Arch Neuropsychiatry. N. 55. Jun 2018. doi.org/10.5152/npa.2017.12731. Disponível em: http://www.noropsikiyatriarsivi.com/en_makaleOzet?id=999. Acesso em 28 set. 2020.

FLICK, Uwe. Desenho da pesquisa qualitativa. Porto Alegre: Artmed, 2009.

GUIMARÃES, Tânia Gonzaga; OUROFINO, Vanessa Terezinha Alves Tentes. Estratégias de Identificação do Aluno com Altas Habilidades/Superdotação. In: FLEITH, Denise de Souza (org.). A Construção de Práticas Educacionais para Alunos com Altas Habilidades/ Superdotação: Orientação a Professores. Brasília: Ministério da Educação, 2007. p. 41-52. Disponível em:

http://www.dominiopublico.gov.br/pesquisa/DetalheObraForm.do?select_action=\&co_obr $\mathrm{a}=124160$. Acesso em: 08 ago 2018.

IRUESTE, Paula; SACO, Ailén; NICOLÁS, Florencia. Dificultades socioemocionales reportadas por los padres y madres de niños e niñas dotados y talentosos, consultantes del Servicio de Neuropsicología, Área Infantil, em Córdoba, Argentina. In: PISKE, Fernanda Hellen Ribeiro; STOLTZ, Tania; COSTA-LOBO, Cristina; ROCHA, Alberto; VÁZQUEZ-JUSTO, Enrique (orgs.). Educação de superdotados e talentosos: Emoção e criatividade. Curitiba: Juruá, 2018. p. 75-88.

LINS, Manuela Ramos Caldas; BORSA, Juliane Callegaro (orgs.). Avaliação psicológica: aspectos teóricos e práticos. Rio de Janeiro: Vozes, 2017.

LÜDKE, M.; ANDRÉ, M. E. D. A. Pesquisa em educação: abordagens qualitativas. $2^{\underline{a}}$ Ed. São Paulo: EPU, 2013.

MATTA, Michael; GRITTI, Emanuela Saveria; LANG, Margherita. Personality assessment of intellectually gifted adults: A dimensional trait approach. Personality and Individual Differences. N. 140, p. 21-26, 2019. Disponível em: https://www.sciencedirect.com/science/article/abs/pii/S0191886918302563. Acesso em 22 nov. 2020.

MENDONÇA, Lurian Dionízio. RODRIGUES, Olga Maria Piazentim Rolim. CAPELLINI, Vera Lucia Messias Fialho. Alunos com altas habilidades/superdotação: como se vêem e como são vistos por seus pais e professores. Educar em Revista, Curitiba, v. 36, p. 1 22. http://dx.doi.org/10.1590/0104-4060.71530. Disponível em:

https://www.scielo.br/pdf/er/v36/1984-0411-er-36-e71530.pdf. Acesso em 20 jul. 2020. 
OLIVEIRA, Christianne do Rocio Storrer. Suporte social familiar e expressão de habilidades socioemocionais do jovem adulto superdotado. Orientadora: Maria de Fatima Joaquim Minetto. 2021. 140f. Dissertação de Mestrado Educação. Universidade Federal do Paraná, Curitiba, 2021.

OLSZEWSKI-KUBILIUS, Paula; LEE, Seon-Young; THOMSON, Dana. Family enviroment and social development in gifted students. Gifted Child Quarterly, Vol. 58 (3), 2014, p. 199-216. DOI: 10.1177/0016986214526430. Disponível em https://journals.sagepub.com/doi/10.1177/0016986214526430. Acesso em 29 jul. 2020.

PALUDO, Karina Inês; LOOS-SANT'ANA, Helga; SANT'ANA-LOOS, René Simonato. Altas Habilidades/Superdotação: Identidade e resiliência. Curitiba: Juruá, 2014.

POLLET, Edith; SCHNELL, Tatjana. Brilliant: but what for? Meaning and subjective wellbeing in the lives of intellectually gifted and academically high-achieving adults. Journal of Happiness Studies, № 18, p. 1459-1484, 2017. DOI 10.1007/s10902-016-9783-4. Disponível em: https://link.springer.com/article/10.1007/s10902-016-9783-4. Acesso em 22. nov 2020.

RENATI, Roberta; BONFIGLIO, Natale Salvatore; PFEIFFER, Steven. Challenges raising a gifted child: Stress and resilience factors within the family. Gifted Education International. Vol. 33(2), p.145-162, 2017. DOI: 10.1177/0261429416650948. Disponível em https://journals.sagepub.com/doi/10.1177/0261429416650948. Acesso em 22 nov. 2020.

RENZULLI, Joseph. Modelo de enriquecimento para toda a escola: um plano abrangente para o desenvolvimento de talentos e superdotação. Revista Educação Especial, v. 27, n. 50, p. 539-562, 2014a. Disponível em https://periodicos.ufsm.br/index.php/educacaoespecial/article/view/14676. Acesso em 10/09/2017.

RENZULLI, Joseph. A concepção de superdotação no modelo dos três anéis: Um modelo de desenvolvimento para a promoção da produtividade criativa. In: VIRGOLIM, Ângela M. R.; KONKIEWITZ, Elisabete Castelon (orgs.). Altas habilidades/superdotação, inteligência e criatividade. Campinas: Papirus, 2014b. Pp. 219-264.

RENZULLI, Joseph. Reexaminando o papel da educação para superdotados e o desenvolvimento de talentos para o Século XXI: uma abordagem teórica em quatro partes. In: VIRGOLIM, Angela (org.). Altas Habilidades/Superdotação: Processos criativos, afetivos e desenvolvimento de potenciais. Curitiba: Juruá, 2018. n.p.

SABATELLA, Maria Lucia Prado; CUPERTINO, Christina M. B. Práticas Educacionais de Atendimento ao Aluno com Altas Habilidades/ Superdotação. In: FLEITH, Denise de Souza (org.). A Construção de Práticas Educacionais para Alunos com Altas Habilidades/ Superdotação: Orientação a Professores. Brasília: Ministério da Educação, 2007. p. 67-79. Disponível em:

http://www.dominiopublico.gov.br/pesquisa/DetalheObraForm.do?select_action=\&co_obra $=124160$. Acesso em: 28 out. 2019 . 
SAMPIERI, Roberto Hernández; COLLADO, Carlos Fernández; LUCIO, María del Pilar Baptista. Metodologia de pesquisa. Porto Alegre: Penso, 2013.

SILVA, Paulo Vinícius Carvalho; FLEITH, Denise de Souza. A influência da família no desenvolvimento da superdotação. Psicologia Escolar e Educacional. v. 12, n. 2, p. 337-346, dez. 2008. doi.org/10.1590/S1413-85572008000200005. Disponível em: http://www.scielo.br/scielo.php?script=sci_arttext\&pid=S1413-

$85572008000200005 \&$ Ing=en\&nrm=iso. Acesso em: 01 jun. 2020.

SILVA, Sheila Perla Maria de Andrade da. Um estudo sobre o perfil de famílias com superdotados no Brasil. 2018. 125 páginas. Dissertação de Mestrado em Processos de Desenvolvimento Humano e Saúde. Instituto de Psicologia, Universidade de Brasília, Brasília, 2018.

SILVERMAN, Linda Kreger. Giftdness 101. New York: Springer Publishing Company, 2013.

VALENTIM, Bernadete de Fátima Bastos; VESTENA, Carla Luciane Blum. Análise do juízo moral em estudantes com altas habilidades/superdotação: uma contribuição educacional. In: PISKE, Fernanda Hellen Ribeiro et al. Processos afetivos e cognitivos de superdotados e talentosos. Curitiba: Prismas, 2017. p. 135-161.

VÖTTER, Bernadette; SCHNELL, Tatjana. Bringing giftedness to bear: generativity, meaningfulness, and self-control as resources for a happy life among gifted adults.

Frontiers in Psychology. V. 10, p. 1-14, 2019. doi.org/10.3389/fpsyg.2019.01972.

Disponível em: https://www.frontiersin.org/articles/10.3389/fpsyg.2019.01972/full. Acesso em 22 nov. 2020.

WEBER, Lidia Natalia Dobrianskyj. PRADO, Paulo Müller. VIEZZER, Ana Paula. BRANDENBURG, Olivia Justen. Identificação de estilos parentais: o ponto de vista dos pais e dos filhos. Psicologia: Reflexão e Crítica, n. 17 (3), p. 323-331, 2004. Disponível em: https://www.scielo.br/pdf/prc/v17n3/a05v17n3.pdf. Acesso em 28 jul. 2020.

\section{Notas}

1 O Laboratório de Pesquisas em Desenvolvimento Humano (LAPEEDH) é vinculado à Universidade Federal do Paraná.

2 WECHSLER, David. WISC-III: Escala de Inteligência Wechsler para Crianças. 3ª ed. São Paulo: Casa do Psicólogo, 2002.

${ }^{3}$ ANGElinI, A. L.; ALVES, I. C. B.; CUSTÓdIO, E. M.; DUARTE, W. F.; DUARTE, J. L. M. Matrizes Progressivas Coloridas de Raven: Escala Especial. São Paulo: CETEPP, 1999.

${ }^{4}$ WECHSLER, David. WAIS III - Escala de inteligência Wechsler para adultos. São Paulo: Casa do Psicólogo, 2015.

This work is licensed under a Creative Commons Attribution-NonCommercial 4.0 International (CC BY-NC 4.0) 